\title{
Construction of a Physical Activity Model for the Elderly
}

\author{
Nam-Hee Kim*, Hyoung-Sook Park**†, Myunghan Choi*** \\ * Department of Nursing, Dong-eui University, Busan Metropolitan City, Korea \\ ** College of Nursing, Pusan National University, Yangsan City, Korea \\ *** College of Nursing and Health Innovation, Arizona State University, Phoenix, AZ, USA
}

\begin{abstract}
$<$ Abstract>
Objectives: The purpose of the study was to test a model of physical activity of elderly living in Korea, determine significant factors contributing the physical activity, and examine significant paths in the model. Methods: A cross-sectional study was conducted using a convenience sample of 207 elderly men and women, aged 60 and older, residing in Busan Metropolitan City. Data were collected from July to August 2009 and analyzed using Predictive Analytics Software (PASW) and Analysis of a Moment Structures (AMOS). Results: The fitness of the modified model was confirmed to be appropriate $\left(\chi^{2}=55.61, \chi^{2} / \mathrm{df}=1.32, \mathrm{p}=.078, \mathrm{RMSEA}=\right.$ .04 , GFI $=.96, \mathrm{AGFI}=.91$, NFI $=.90, \mathrm{NNFI}=.94, \mathrm{CFI}=.97$, PNFI $=.48)$. The elder's age, previous exercise behavior, and self-efficacy were significant in explaining the variance in their physical activity. We found that (a) perceived health status, perceived benefits, perceived barriers, and social support directly affected self-efficacy; (b) previous exercise behavior and perceived health status directly affected perceived benefits; (c) previous exercise behavior directly affected perceived barriers; and (d) and education level, extent of pocket money, and economic level directly affected social support. Conclusions: The younger the age, the more previous exercise experience, and the higher the self-efficacy, the more S. Korean elders demonstrated improved physical activity.
\end{abstract}

Key words: Elderly, Physical activity, Self-efficacy

\section{I . Introduction}

\section{Background}

South Korean society has already become an aging society, with $10.3 \%$ of the population over age 65 years in 2008 (Korea National Statistical Office, 2008). The aging population in S. Korea is expected to pose a major challenge to the country's socioeconomic progress in the next century. By the year 2030, the aging population is expected to increase by $17.1 \%$, from $7.2 \%$ in 2000 to $24.3 \%$ in 2030 (Korea National Statistical Office, 2010). The New Health Plan 2010 in Korea, Healthy Japan 21 in Japan, and Healthy People 2020 in the United States have published effective methods for improving national health of all, as actions for public health are desperately needed to prevent degenerative diseases in the elderly (Park, Kim, Kang, $\&$ Park, 2007). The emphases of these global health plans are on improving health, fitness, and quality of life through daily physical activity.

Physical activity is an important health promotion behavior in the elderly. Numerous studies have reported that daily physical activity decreases mortality and prevents cardiovascular disease, type 2 diabetes, hypertension, various types of cancer, osteoporosis, anxiety, and depression (Warburton, Nicol, \& Bredin, 2006). Daily physical activity also raises life expectancy in the elderly, decreases chronic pain due to arthritis, prevents falls or fall-related fractures, and improves the ability to maintain functional independence (Pan et al., 2009).

Corresponding author : Hyoung-Sook Park

College of Nursing, Pusan National University Beomeo-ri, Mulgeum-eup, Yangsan-si, Gyeongsangnam-do, 626-870, Korea

Tel: 82-51-510-8336 Fax: 82-51-510-8308 E-mail: haedang@pusan.ac.kr

This article is a revision of the first author thesis from the Pusan National University of Korea

- Received: 2013.01.15 - Revised: 2013.03.06 - Accepted: 2013.03.18 
Despite these benefits from physical activity, according to the 2008 Korean National Health and Nutrition Examination Surveys(KNHANES), the rate of its practice decreases with advancing age and has been recorded as $12.0 \%$ and $5.5 \%$ in the elderly aged 60-69 years and over 70 years respectively (Korean Ministry of Health and Welfare, 2010). Factors known to influence physical activity in the elderly are age, education level, economic level, previous exercise behavior, perceived health status (Lee \& Laffrey, 2006), self-efficacy (Conn, Burks, Pomeroy, Ulbrich, \& Cochran, 2003), perceived benefits (Hwang \& Chung, 2008), perceived barriers (Rhodes et al., 1999), and social support (Wu \& Porell, 2000).

Most of these variables were examined by Pender (1996)'s health promotion model (HPM), which focuses on multi-dimensional characteristics of individuals such as sociodemographic and cognitive/perceptive factors and the practice of health promotion behaviors. Pender's HPM has been applied to predict and mediate health promotion behaviors. Because physical activity is a complex and dynamic process affected by physiological, psychological, social, and behavioral factors (Sallis \& Hovell, 1990), Pender's HPM is considered to be appropriate to explain physical activity or a sub-domain of health promotion behaviors.

In examining physical activity or exercise based on Pender's HPM, various overseas studies have been conducted with adolescents (Wu \& Pender, 2002), the elderly (Conn et al., 2003) and adults (Ma, Lane, \& Laffrey, 2008). However, the few studies in Korea have been restricted to arthritis patients (Suh, 1999) an dearly middle-aged women (Lee, 1999). The Pender model has been applied to the research investigating health promoting factors including physical activity in the elderly (Shin, Kang, Park, Cho, \& Heitkemper, 2008). It is necessary to identify the factors that predict physical activity among elderly to develop effective interventions that can improve the quality of life of these populations.

In the meantime, the interest in the exercise environment as a factor affecting physical activity has attracted researchers' attention. The exercise environment provokes appropriate opportunities and stimuli to do exercise and is related with exercise activities. When the elderly can easily access safe and comfortable places for exercise (Dawson, Hillsdon, oller, \& Foster, 2007) and when the elderly have a high possibility of utilizing facilities for exercise (Panetal., 2009), they perform physical activity comfortably and voluntarily.

Although attention has become directed at promoting physical activity in the elderly, most studies on physical activity have only conducted fragmentary investigations on the correlation among variables, so a comprehensive approach to these variables influencing the physical activity of the elderly is considered necessary. Therefore, this study aims to construct a physical activity model for the elderly to aid in the establishment of suitable health promotion strategies to promote physical activity among the elderly by comprehensively investigating the influence and the specific pathways of various factors that affect physical activity as confirmed by applying Pender's HPM and by conducting a literature review.

\section{Purpose}

This study was conducted to determine the factors affecting the physical activity of the elderly utilizing senior welfare centers, to examine the correlation among the factors and to establish a model to explain the physical activity of the elderly. The detailed study objectives are as follows.

1) A hypothesized model about the physical activity of the elderly is constructed by focusing on factors influencing the physical activity that were confirmed through literature review.

2) The direct and indirect effects of variables on physical activity are examined.

3) The explanatory power of the model about the physical activity of the elderly is tested using causal modeling techniques (AMOS).

\section{Conceptual framework}

The conceptual framework and hypothesized model of this study are constructed based on Pender's HPM and factors that 
have been reported to affect physical activity in the elderly are determined through literature review. Although Pender's HPM showed a pathway from self-efficacy to perceived barriers, many studies based on Pender's HPM that investigated physical activity or exercise as a dependent variable (Conn et al., 2003; Lee, 1999; Lee \& Laffrey, 2006; Ma et al., 2008; Wu \& Pender, 2002) found that perceived barriers influenced self-efficacy. Therefore, this study examines a pathway from perceived barriers to self-efficacy.

In the physical activity model for the elderly, the extraneous variables are age, socioeconomic factor, previous exercise behavior, perceived health status and exercise environment, endogenous variables are self-efficacy, perceived benefits, perceived barriers, and social support, and the outcome variable is physical activity. The conceptual framework of the model is that these five extraneous variables influence physical activity directly or indirectly through the four endogenous variables. This hypothesized model is presented diagrammatically in [Figure 1].

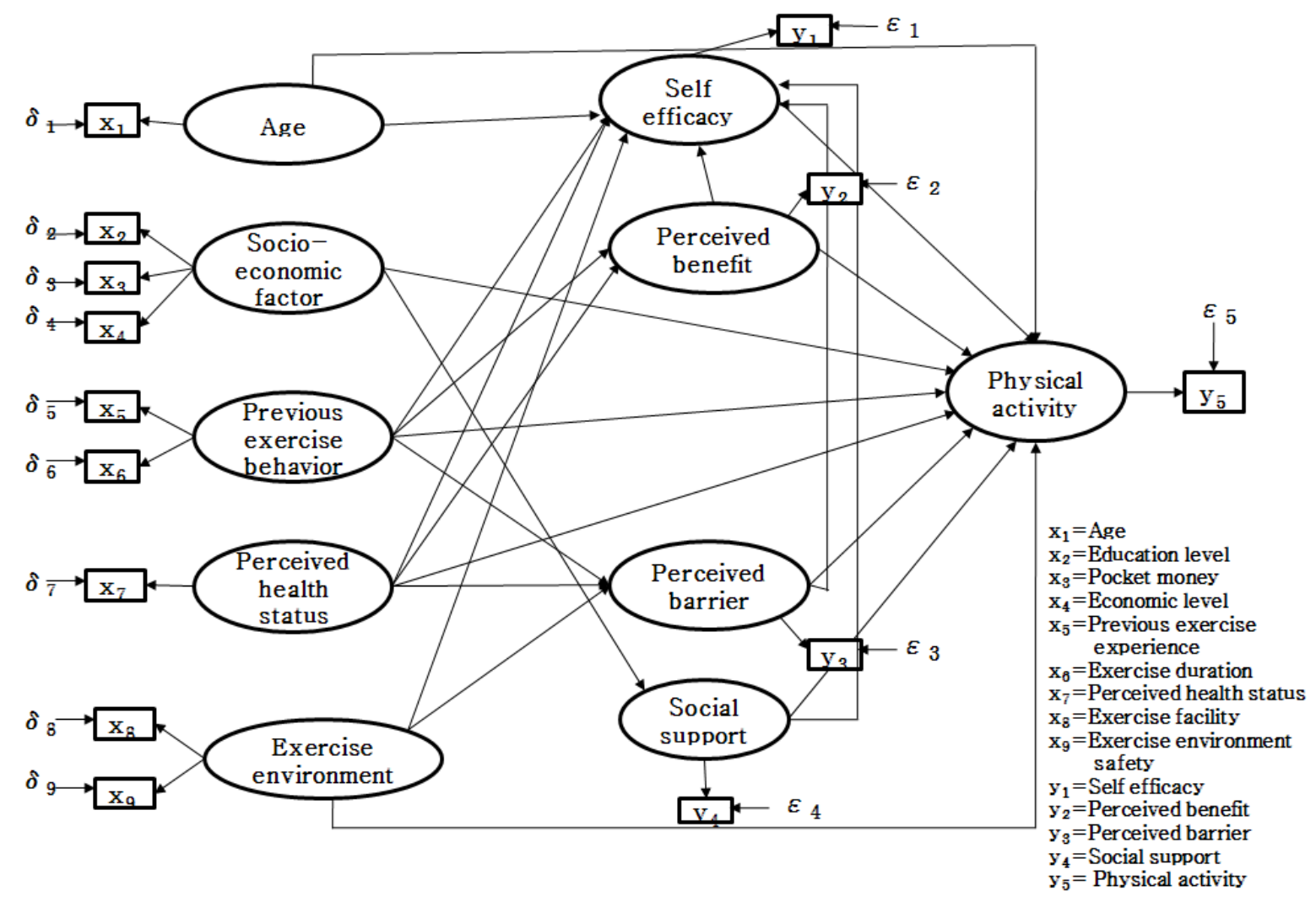

[Figure 1] The hypothetical model

\section{Methods}

\section{Design and Sample}

A cross-sectional exploratory design, with a convenience sample of 207 elderly men and women, aged 60 and older, was used to test the model of physical activity of the elderly in S. Korea. The inclusion criteria were participants who (a) were able to read, speak and write in Korean; (b) were able to communicate with interviewers; (c) were registered as members of senior welfare centers located in Busan Metropolitan City; and (d) agreed to participate in the study. The participants were 
informed of the study purpose and confidentiality. They were also informed that they could withdraw from the study at any time and that all data collected in the questionnaire would remain anonymous.

Those who signed written consent forms were then given a questionnaire to complete. After they completed the survey, participants received a 5,000-won (equivalent to $\$ 5.00 \mathrm{US}$ ) gift card in appreciation for their involvement. A total of 250 sample size was decided upon based on $\alpha=0.05$, $\mathrm{df}=49,1-\beta=0.5$, null RMSEA $=0.05$, and alternative RMSEA $=0.07$ (Preacher, Cai, \& MacCallum, 2007). Lee (1990) also suggested that a sample size of at least 200 could facilitate proper model outcomes with good fit indices.

\section{Measures}

Physical activity was measured with the Physical Activity Scale for the Elderly (PASE) developed by Washburn, Smith, Jette, and Janney (1993) and translated into Korean by Choe, Kim, Chae, Jeon, and You (2004). The PASE consists of 10 items, and each question contains subscales. The weighting of each item varied according to the type and degree of physical activity. The physical activity was measured with 6 items out of the 10 PASE items in this study. Four items were excluded from the data analysis because we found that the deviations of housework item scores were severe in the pilot study. The physical activity was measured with 6 items in this study, with a higher score indicating a higher level of physical activity. The score ranged from 0 to 257.89 . The test-retest reliability was .75 and .94 in the studies of Washburn et al. (1993) and Choe et al. (2004) respectively, and it was .81 in this study, with a 2-week interval between the two tests. Choe et al. (2004) administered the PASE based on various physical activities focusing on a physical activity dairy and a global activity self-assessment to exam test-retest reliability. Therefore, this study also utilized the test-retest reliability.

Self-efficacy was measured with a self-efficacy scale developed by Marcus, Selby, Niaura, and Rossi (1992) and translated into Korean by Lee and Chang (2001). The scale consists of 5 items ranging from 1 (strongly disagree) to 4 (strongly agree). Cronbach's $\alpha$ was .82 and .75 in the two studies respectively, compared with .92 in our study.

Perceived benefits and perceived barriers were measured with a scale developed by Sechrist, Walker, and Pender (1987) and translated into Korean and verified by Jang and Shin (1999). This scale contains 40 items consisting of 27 perceived benefits and 13 perceived barriers. Perceived benefits of exercise, including internal and external benefits, were scored on a scale ranging from 1 (strongly disagree) to 4 (strongly agree), with a higher score indicating a higher level of perceived benefits. Barriers to exercise are the personal losses following the performance of exercise and were scored on a scale ranging from 1 (strongly disagree) to 4 (strongly agree), with a higher score indicating a greater level of perceived barriers. Cronbach's $\alpha$ of perceived benefits and perceived barriers was .99 and .92 respectively in the study of Jang and Shin (1999), compared with .95 and .82 respectively in our study.

Social support was measured by the scale of exercise-related social support developed by Sallis, Grossman, Pinski, Patterson, and Nader (1987) and was supplemented and modified by Choi (2005). It included 7 items consisting of material, emotional, informational, and appraisal support related to exercise that were scored on a 5-point Likert scale; a higher score indicates a greater level of social support. Cronbach's $\alpha$ was .89 in the study of Choi (2005), compared with .94 in our study.

Education level, sufficiency of monthly allowance, and economic level were measured as socioeconomic factors. Scores for education level ranged from 1 (no educational background) to 6 (graduate school), monthly allowance from 1 (very insufficient) to 5 (very sufficient), and economic level from 1 (very low) to 5 (very high). Monthly allowance is defined as how much money the elderly person gets from their adult children per month. (In S. Korea, giving parents monthly allowance as an appreciation is common.) Economic level is defined as the elderly person's current monthly income (e.g., from a pension) over and above monthly allowance.

Previous exercise behavior was measured with two items used by Lee (1999) to determine whether exercise had been done regularly for over 6 months and to specify the duration of 
regular exercise performance. The experience and non-experience of regular exercise were scored with 2 points and 1 point respectively.

Perceived health status was measured by using the scale of self-perceived health status developed by Lawstone, Moss, Fulcomer, and Kleban (1982) that was used in the study of Kim (2000). The scale comprises 3 items scored on a 5-point Likert scale, ranging from 3 points to 15 points, with a higher score indicating a greater level of perceived health status. Cronbach's $\alpha$ was .76 and .88 in the studies of Lawstone et al. (1982) and Kim (2000) respectively, compared with .88 in our study.

The exercise environment was measured by a 4-item scale developed by Choe, Hah, Kim, Yi, and Choi (2008) and was modified based on previous studies about exercise environment and interviews. We utilized 2 items: the existence of facilities for exercise near the home (equipment at home or in sports centers near the home) and the safety of the exercise environment. The items were answered with Yes (2 points) or No (1 point). Cronbach's $\alpha$ of the scale was .72 in the study of Choe et al. (2008), compared with .82 in our study.

\section{Procedures}

After the researcher and two research assistants (RAs) had explained the study purpose to the managers of the senior welfare centers and secured their cooperation while visiting the centers, written consent for participation in this study was obtained directly from the study participants, followed by data collection. Data collection was from July 6, 2009, to August 25, 2009. To maintain the consistency in the administration of the questionnaire, the researcher explained and demonstrated the content, intention, methods, and procedures of the survey to two RAs in the Department of Geriatric Nursing. Completing the questionnaires took approximately 30 minutes.

\section{Data Analysis}

A total of 207 samples were analyzed after excluding 43 incomplete samples. The demographic data, reliability of the scales, and correlations were analyzed using Predictive Analytics
Software (PASW, Version 17). A structural equation model (SEM) with Analysis of a Moment Structures (AMOS, Version 7) was used to examine the model fitness to the sample data. Total, direct, and indirect effects were calculated based on partial path regression coefficients. We used standardized partial path regression coefficients for these effects, which provide interpretative advantages because all variables are transformed approximately to a common scale, facilitate comparisons between coefficients, and permit a comparison of the magnitude of effects associated with two or more independent variables on common dependent variables (Hotchkiss, 1976). Multiple squared correlations (R2) were assessed to explain the relative contribution of each indicator to the physical activity. Parameters were estimated with the maximum likelihood method (MLM). Squared multiple correlation (SMC), modification index (MI), $\chi^{2}$ statistics, p-value, root mean square error of approximation (RMSEA), goodness of fit index (GFI), adjusted goodness of fit index (AGFI), normed fit index (NFI), non-normed fit index (NNFI), comparative fit index (CFI), $\chi^{2} / \mathrm{df}$, and parsimony normed fit index (PNFI) were used to estimate the model fit.

\section{Results}

\section{General characteristics}

The mean age of participants was 69.7 years, and 27.6\% were aged 65-69 years. Just over half $(52.2 \%)$ of the subjects were female. One-third (34.3\%) of the participants graduated from high school, and Buddhism was the dominant religion (48.3\%). A total of $65.7 \%$ reported that their economic level was middle, and $60.4 \%$ reported that their monthly allowance was at the ordinary level. A majority (54.1\%) lived with their spouses. Eighty-five percent and $72.5 \%$ reported that they did not smoke or drink respectively, and $70.0 \%$ exercised regularly. Approximately $69 \%$ $(68.6 \%)$ had 1 or 2 diseases, with 6.1 being the average number of years that participants had the disease(s). Among the diseases, $28.7 \%$ reported that they had musculoskeletal disease, followed by $26.2 \%$ with hypertension, $12.3 \%$ with gastrointestinal disease, and $10.7 \%$ with an eye or ear disease. 


\section{Descriptive Statistics of Variables and Correlation among Variables}

The average scores were $47.15,12.75,79.51,22.60,21.09$, and 9.29 for physical activity, self-efficacy, perceived benefits, perceived barriers, social support, and perceived health status, respectively. For correlations, dummy coding was used for nominal variables. Physical activity was significantly related to age $(\mathrm{r}=-.20, \mathrm{p}<.01)$, education level $(\mathrm{r}=.23, \mathrm{p}<.01)$, exercise experience $(\mathrm{r}=.36, \mathrm{p}<.01)$, period of exercise $(\mathrm{r}=.39, \mathrm{p}<.01)$, perceived health status $(\mathrm{r}=.26, \mathrm{p}<.01)$, facilities for exercise $(\mathrm{r}$ $=.22, \mathrm{p}<.01)$, safety of exercise environment $(\mathrm{r}=.16, \mathrm{p}<.05)$, self-efficacy $(r=.35, p<.01)$, perceived benefits $(r=.24, p<.01)$, perceived barriers $(\mathrm{r}=-.18, \mathrm{p}<.05)$, and social support $(\mathrm{r}=.27$, $\mathrm{p}<.01)<$ Table 1>.

$<$ Table 1> Correlations among variables

$(\mathrm{N}=207)$

\begin{tabular}{|c|c|c|c|c|c|c|c|c|c|c|c|c|c|}
\hline & $\mathbf{x}_{1}$ & $\mathbf{x}_{2}$ & $\mathbf{x}_{\mathbf{3}}$ & $\mathbf{x}_{4}$ & $\mathbf{X}_{5}$ & $\mathbf{X}_{6}$ & $\mathbf{X}_{7}$ & $\mathrm{X}_{8}$ & $\mathbf{X}_{9}$ & $\mathbf{y}_{1}$ & $\mathbf{y}_{2}$ & $\mathbf{y}_{3}$ & $y_{4}$ \\
\hline $\mathrm{x}_{2}$ & $\begin{array}{r}-.09 \\
(.216)\end{array}$ & & & & & & & & & & & & \\
\hline$x_{3}$ & $\begin{array}{r}.01 \\
(.838)\end{array}$ & $\begin{array}{r}.24 \\
(<.001)\end{array}$ & & & & & & & & & & & \\
\hline $\mathrm{x}_{4}$ & $\begin{array}{r}.09 \\
(.207)\end{array}$ & $\begin{array}{r}.30 \\
(<.001)\end{array}$ & $\begin{array}{r}.72 \\
(.<001)\end{array}$ & & & & & & & & & & \\
\hline $\mathrm{x}_{5}$ & $\begin{array}{r}-.03 \\
(.693)\end{array}$ & $\begin{array}{r}.18 \\
(.011)\end{array}$ & $\begin{array}{r}.12 \\
(.082)\end{array}$ & $\begin{array}{r}.06 \\
(.391)\end{array}$ & & & & & & & & & \\
\hline $\mathrm{x}_{6}$ & $\begin{array}{r}.05 \\
(.483)\end{array}$ & $\begin{array}{r}.19 \\
(.006)\end{array}$ & $\begin{array}{r}-.01 \\
(.918)\end{array}$ & $\begin{array}{r}.03 \\
(.651)\end{array}$ & $\begin{array}{r}.47 \\
(<.001)\end{array}$ & & & & & & & & \\
\hline $\mathrm{x}_{7}$ & $\begin{array}{r}.02 \\
(.815)\end{array}$ & $\begin{array}{r}.29 \\
(<.001)\end{array}$ & $\begin{array}{r}.19 \\
(.006)\end{array}$ & $\begin{array}{r}.21 \\
(.002)\end{array}$ & $\begin{array}{r}.30 \\
(<.001)\end{array}$ & $\begin{array}{r}.31 \\
(<.001)\end{array}$ & & & & & & & \\
\hline $\mathrm{x}_{8}$ & $\begin{array}{r}-.03 \\
(.639)\end{array}$ & $\begin{array}{r}.04 \\
(.582)\end{array}$ & $\begin{array}{r}.09 \\
(.179)\end{array}$ & $\begin{array}{r}.09 \\
(.187)\end{array}$ & $\begin{array}{r}.21 \\
(.002)\end{array}$ & $\begin{array}{r}.06 \\
(.426)\end{array}$ & $\begin{array}{r}.11 \\
(.124)\end{array}$ & & & & & & \\
\hline $\mathrm{X}_{9}$ & $\begin{array}{r}-.05 \\
(.486) \\
\end{array}$ & $\begin{array}{r}.14 \\
(.050)\end{array}$ & $\begin{array}{r}.13 \\
(.083)\end{array}$ & $\begin{array}{r}.20 \\
(.004) \\
\end{array}$ & $\begin{array}{r}.21 \\
(.002) \\
\end{array}$ & $\begin{array}{r}.09 \\
(.203)\end{array}$ & $\begin{array}{r}.20 \\
(.005)\end{array}$ & $\begin{array}{r}.58 \\
(<.001)\end{array}$ & & & & & \\
\hline $\mathrm{y}_{1}$ & $\begin{array}{r}-.04 \\
(.542 \\
\end{array}$ & $\begin{array}{r}.14 \\
(.041)\end{array}$ & $\begin{array}{r}.09 \\
(.200)\end{array}$ & $\begin{array}{r}.06 \\
(.365) \\
\end{array}$ & $\begin{array}{r}.39 \\
(<.001)\end{array}$ & $\begin{array}{r}.21 \\
(.003)\end{array}$ & $\begin{array}{r}.43 \\
(<.001)\end{array}$ & $\begin{array}{r}.16 \\
(.018)\end{array}$ & $\begin{array}{r}.17 \\
(.013)\end{array}$ & & & & \\
\hline $\mathrm{y}_{2}$ & $\begin{array}{r}-.11 \\
(.116)\end{array}$ & $\begin{array}{r}.05 \\
(.497)\end{array}$ & $\begin{array}{r}.02 \\
(.761)\end{array}$ & $\begin{array}{r}.00 \\
(.965)\end{array}$ & $\begin{array}{r}.29 \\
(<.001)\end{array}$ & $\begin{array}{r}.16 \\
(.018)\end{array}$ & $\begin{array}{r}.29 \\
(<.001)\end{array}$ & $\begin{array}{r}.10 \\
(.141)\end{array}$ & $\begin{array}{r}.12 \\
(.085)\end{array}$ & $\begin{array}{r}.55 \\
(<.001)\end{array}$ & & & \\
\hline $\mathrm{y}_{3}$ & $\begin{array}{r}.04 \\
(.529)\end{array}$ & $\begin{array}{r}-.11 \\
(.131)\end{array}$ & $\begin{array}{r}-.005 \\
(.944)\end{array}$ & $\begin{array}{r}-.09 \\
(.207)\end{array}$ & $\begin{array}{r}-.27 \\
(<.001)\end{array}$ & $\begin{array}{r}-.24 \\
(.001)\end{array}$ & $\begin{array}{r}-.25 \\
(<.001)\end{array}$ & $\begin{array}{r}-.22 \\
(.001)\end{array}$ & $\begin{array}{r}-.16 \\
(.018)\end{array}$ & $\begin{array}{r}-.26 \\
(<.001)\end{array}$ & $\begin{array}{r}-.09 \\
(.182)\end{array}$ & & \\
\hline $\mathrm{y}_{4}$ & $\begin{array}{r}-.09 \\
(.222)\end{array}$ & $\begin{array}{r}.27 \\
(<.001)\end{array}$ & $\begin{array}{r}.14 \\
(.041)\end{array}$ & $\begin{array}{r}.23 \\
(.001)\end{array}$ & $\begin{array}{r}.28 \\
(<.001)\end{array}$ & $\begin{array}{r}.08 \\
(.240)\end{array}$ & $\begin{array}{r}.20 \\
(.004)\end{array}$ & $\begin{array}{r}.25 \\
(<.001)\end{array}$ & $\begin{array}{r}.22 \\
(.002)\end{array}$ & $\begin{array}{r}.36 \\
(<.001)\end{array}$ & $\begin{array}{r}.30 \\
(<.001)\end{array}$ & $\begin{array}{r}-.14 \\
(.049)\end{array}$ & \\
\hline $\mathrm{y}_{5}$ & $\begin{array}{r}-.20 \\
(.004)\end{array}$ & $\begin{array}{r}.23 \\
(.001)\end{array}$ & $\begin{array}{r}.07 \\
(.344)\end{array}$ & $\begin{array}{r}.02 \\
(.731)\end{array}$ & $\begin{array}{r}.36 \\
(<.001)\end{array}$ & $\begin{array}{r}.39 \\
(<.001)\end{array}$ & $\begin{array}{r}.26 \\
(<.001)\end{array}$ & $\begin{array}{r}.22 \\
(.002)\end{array}$ & $\begin{array}{r}.16 \\
(.023)\end{array}$ & $\begin{array}{r}.35 \\
(<.001)\end{array}$ & $\begin{array}{r}.24 \\
(<.001)\end{array}$ & $\begin{array}{r}-.18 \\
(.012)\end{array}$ & $\begin{array}{r}.27 \\
(<.001)\end{array}$ \\
\hline
\end{tabular}

$\mathrm{x}_{1}=$ Age; $\mathrm{x}_{2}=$ Education level; $\mathrm{x}_{3}=$ Monthly allowance; $\mathrm{x}_{4}=$ Economic level; $\mathrm{x}_{5}=$ Previous exercise experience; $\mathrm{x}_{6}=$ Exercise duration; $\mathrm{x}_{7}=$ Perceived health status; $\mathrm{x}_{8}=$ Exercise facility; $\mathrm{x}_{9}=$ Exercise environment safety

$y_{1}=$ Self efficacy; $y_{2}=$ Perceived benefit; $y_{3}=$ Perceived barrier; $y_{4}=$ Social support; $y_{5}=$ Physical activity

\section{Testing the Hypothesized Model}

The hypothesized model consisted of three latent variables (socioeconomic factors, previous exercise behavior, and exercise environment) and seven observed variables (age, perceived health status, self-efficacy, perceived benefits, perceived barriers, social support, and physical activity). The total variance explained physical activity was $34 \%$, with direct and indirect influences in the model. The direct influences on physical activity were age, 
self-efficacy, perceived benefit, socioeconomic factors, perceived exercise behavior, perceived barriers, social support, and exercise environment. The indirect influences on physical activity were socio-economic factor through social support; previous exercise behavior through perceived benefits and perceived barrier; perceived health status through self-efficacy and perceived benefits [Figure 1]. The $\chi^{2}$, RMSEA, GFI, AGFI, NFI, NNFI, CFI, $\chi^{2} / \mathrm{df}$ and PNFI were $97.78(\mathrm{p}<.001), .07, .94, .87, .87$, $.86, .92,2.00$ and .47 respectively. While GFI, CFI and $\chi^{2} / \mathrm{df}$ indicated a good fit, $\chi^{2}$, RMSEA, AGFI, NFI, NNFI and PNFI showed poor fit. If $\chi^{2}$ statistic is greater than 0.05 , RMESA 0.08 or less, GFI greater than 0.9 , AGFI greater than 0.9 , NFI greater than 0.9 , NNFI greater than 0.9 , CFI greater than 0.9, PNFI greater than 0.9 , the goodness of fit of the model is good.

One of the most important aims of SEM is to simplify a model while maintaining its fitness of indices. In reviewing the selected indexes of fit in a hypothesized model, a modification in specification is needed to determine a model that best represents the sample data. The hypothesized model was modified by deleting statistically insignificant paths with very low p-values to enhance the model's simplicity and by maintaining the fitness through repeated consideration of modification indices (MI). MIs are computed for all parameters implicitly assumed to be zero and explicitly fixed to zero. Large MIs indicate the presence of factor cross-loading (Byrne, 2001). The value of MIs in our study ranged from 4.06 to 9.39. We focused solely on MIs representing cross-loadings and error covariances. There were no substantially larger MIs than those remaining. This indicates there were minimal misspecified error covariances or measurement errors. By connecting the variables with the highest MI first, the error term between social support and perceived benefits that showed that the highest MI in the hypothesized model was connected and then the error term between the experience of exercise and self-efficacy was connected step by step. Insignificant paths with very low p-values from age, previous exercise behavior, and exercise environment to self-efficacy and paths from perceived health status and exercise environment to perceived barriers were removed and modified.

The modified model consisted of the same latent and observed variables that the hypothesized model indicated. The total variance explained in physical activity was 37\%, with direct significant influences from age ( $\beta=-.18, p=.003)$, self-efficacy $(\beta=.19, \mathrm{p}=.14)$, and previous exercise experience $(\beta=.50$, $\mathrm{p}=.000)$. The indirect effects were (a) previous exercise ( $\beta=$ $.22, \mathrm{p}=.027$ ) on physical activity through perceived benefits, (b) previous exercise $(\beta=-.41, \mathrm{p}=.000)$ on physical activity through perceived barriers, and (c) socioeconomic factors $(\beta=$ $.53, \mathrm{p}=.000$ ) on physical activity through social support. Through these modifications, the fitness of the modified model was significantly improved. The fitness indices of the hypothesized and modified models were compared, as shown in $\langle$ Table $2>$.

$<$ Table 2> Fitness indices for the hypothetical model and the modified model

$(\mathrm{N}=207)$

\begin{tabular}{|c|c|c|c|}
\hline Content & Value of hypothetical model & Value of modified model & Evaluation criteria \\
\hline$x^{2}$ & 97.78 & 55.61 & \\
\hline df & 49 & 42 & \\
\hline p-value & $<.001$ & .078 & $>.05$ \\
\hline RMSEA & .07 & .04 & $\leq .05$ \\
\hline GFI & .94 & .96 & $\geq .90$ \\
\hline AGFI & .87 & .91 & $\geq .90$ \\
\hline NFI & .87 & .90 & $\geq .90$ \\
\hline NNFI & .86 & .94 & $\geq .90$ \\
\hline CFI & .92 & .97 & $\geq .90$ \\
\hline$x^{2} / d f$ & 2.00 & 1.32 & $<3$ \\
\hline PNFI & .47 & .48 & larger value is better \\
\hline
\end{tabular}


The difference in $\chi^{2}$ statistics between the two models was NNFI $=.94$, CFI $=.97$ and PNFI $=.48$, indicating a good 97.78-55.61 $=42.17$, and $\chi^{2} / \mathrm{df}$ was 1.32 . The modified model model fit [Figure 2]. showed RMSEA $=.04$, GFI $=.96$, AGFI $=.91$, NFI $=.90$,

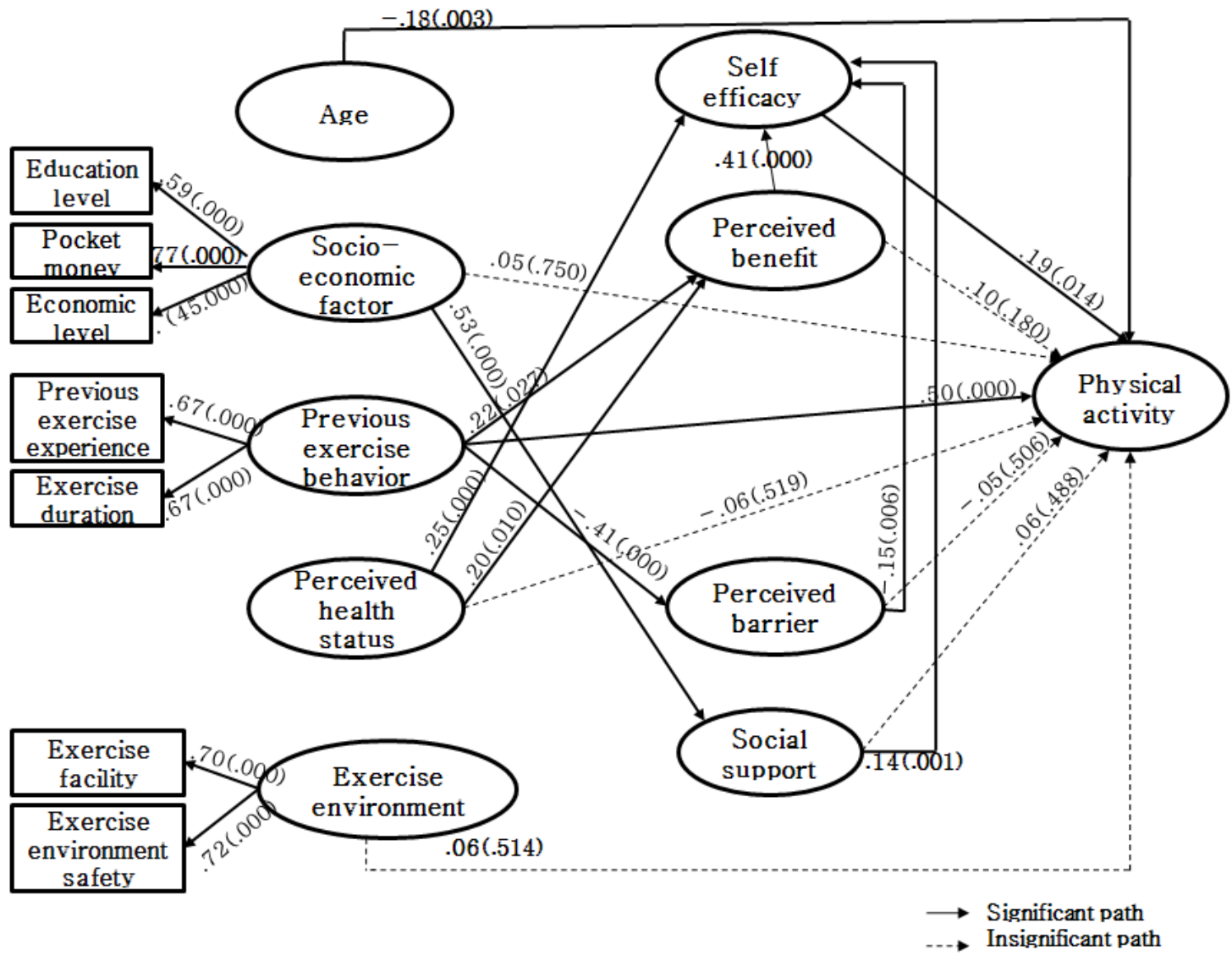

[Figure 2] Path diagram for the modified model

Variables affecting physical activity were age $(\mathrm{p}=.003)$, previous exercise behavior $(\mathrm{p}=.000)$ and self-efficacy $(\mathrm{p}=$ .014). Younger age, an experience of regular exercise, a longer period of previous exercise, and higher self-efficacy were associated with higher physical activity scores, accounting for a total $37 \%$ of variance in physical activity $<$ Table $3>$.

$<$ Table 3> Direct, indirect, and total effects in the modified model

\begin{tabular}{|c|c|c|c|c|c|}
\hline $\begin{array}{c}\text { Endogeneous } \\
\text { variables }\end{array}$ & $\begin{array}{l}\text { Exogeneous } \\
\text { variables }\end{array}$ & $\begin{array}{c}\text { Standardized } \\
\text { direct } \\
\text { effect }\end{array}$ & $\begin{array}{c}\text { Standardized } \\
\text { indirect } \\
\text { effect }\end{array}$ & $\begin{array}{c}\text { Standardized } \\
\text { total } \\
\text { effect }\end{array}$ & $p$ \\
\hline \multirow[t]{4}{*}{ Self efficacy } & Perceived health status & .25 & .09 & .34 & $<.001$ \\
\hline & Perceived benefit & .41 & & .41 & $<.001$ \\
\hline & Perceived barrier & -.15 & & -.15 & .006 \\
\hline & Social support & .14 & & .14 & .001 \\
\hline
\end{tabular}




\begin{tabular}{|c|c|c|c|c|c|}
\hline $\begin{array}{l}\text { Endogeneous } \\
\text { variables }\end{array}$ & $\begin{array}{l}\text { Exogeneous } \\
\text { variables }\end{array}$ & $\begin{array}{c}\text { Standardized } \\
\text { direct } \\
\text { effect }\end{array}$ & $\begin{array}{l}\text { Standardized } \\
\text { indirect } \\
\text { effect }\end{array}$ & $\begin{array}{c}\text { Standardized } \\
\text { total } \\
\text { effect }\end{array}$ & $p$ \\
\hline \multirow[t]{2}{*}{ Perceived benefit } & $\begin{array}{l}\text { Previous exercise } \\
\text { Behavior }\end{array}$ & .22 & & .22 & .027 \\
\hline & Perceived health status & .20 & & .20 & .010 \\
\hline Perceived barrier & $\begin{array}{l}\text { Previous exercise } \\
\text { Behavior }\end{array}$ & -.41 & & -.41 & $<.001$ \\
\hline Social support & Socioeconomic factor & .53 & & .53 & $<.001$ \\
\hline Physical & Age & -.18 & & -.18 & .003 \\
\hline \multirow[t]{8}{*}{ Activity } & Socioeconomic factor & .05 & .05 & .10 & .750 \\
\hline & $\begin{array}{l}\text { Previous exercise } \\
\text { Behavior }\end{array}$ & .50 & -.02 & .48 & $<.001$ \\
\hline & Perceived health status & -.06 & .06 & .00 & .519 \\
\hline & Exercise environment & .06 & & .06 & .514 \\
\hline & Self efficacy & .19 & & .19 & .014 \\
\hline & Perceived benefit & .10 & -.03 & .07 & .180 \\
\hline & Perceived barrier & -.05 & .08 & .03 & .506 \\
\hline & Social support & .06 & .03 & .09 & .488 \\
\hline
\end{tabular}

\section{Discussion}

This current study determined the factors affecting the physical activity of the elderly who utilized senior welfare centers, and it investigated the paths linking these factors based on Pender's HPM and a literature review. Variables in this study covered a lot of physical activity related papers were mainly used variables. Future research are needed to develop physical activity model for the elderly that include other variables, such as, self-esteem, social norm/subjective norm, exercise-related affect/emotion, exercise commitment.

The combined explanatory power of the physical activity model was $37 \%$, which was higher than that in the studies of Wu and Pender (2002; 26\%) and Ma et al. (2008; 23.3\%). As an explanatory power of over $40 \%$ is considered to be high in a social survey, although experimental studies need a power of over $70-80 \%$ (Lee, 1990), the explanatory power of this study at $37 \%$ meant that this model explained the physical activity of the elderly relatively well. The association of younger age with higher physical activity in the elderly indicated that age had a direct and significant effect on physical activity. Therefore, when physical activity or exercise programs are applied to the elderly, age-differentiated programs will be more successful.

Our findings, which demonstrated that $70 \%$ of the participants had engaged in regular exercise in the past and that previous exercise behavior showed the strongest effect on the physical activity of the elderly, were consistent with the findings of Lee and Laffrey (2006). In addition, previous exercise behavior significantly influenced perceived benefits and perceived barriers. Our findings also indicated that participants with past exercise activity in their youth continuously maintained their physical activity. These findings stress that the importance of physical activity should be emphasized from middle age or young adulthood and that therefore, when physical activity or exercise programs are applied to the elderly, age-differentiated programs will be more successful. 
Self-efficacy was the most significant direct factor on the physical activity of the elderly, which was consistent with the findings of a previous study that self-efficacy was associated with increased physical activity (Hwang \& Chung, 2008; Rhodes et al., 1999). In this study, perceived health status, perceived benefits, perceived barriers, and social support indirectly influenced physical activity through self-efficacy. Accordingly, self-efficacy was one of the most influential factors for the elderly to begin and continue physical activity. Therefore, self-efficacy of the elderly needs to be promoted by emphasizing the various advantages of regular physical activity rather than the personal losses that are perceived as barriers to physical activity. Findings demonstrate that interventions focused on increasing physical activity that reflect consideration to enhance self-efficacy should concentrate on a providing positive PA experiences that reduce discomfort and activating social support of efficacy enhancement, and persuading elderly that physical activity is an important factor to improve quality of life.

Education level, sufficiency of monthly allowance, and economic level did not have any significant effect on the physical activity of the elderly, which is consistent with the report of Speake, Cowart, and Pellet (1989) that income and education did not significantly affect the performance of exercise in the elderly. However, our study results are not consistent with those of Lee and Laffrey (2006), who demonstrated that socioeconomic factors, including education level, sufficiency monthly allowance and economic level in community-dwelling elderly significantly influenced physical activity.

Perceived health status directly affected self-efficacy and perceived benefits but did not show any direct effect on physical activity. This finding was different from that of Chang, Lee, and Park (2002), who reported that elderly who perceived themselves to be healthy exercised more regularly and participated in social activities more vigorously than those who did not perceive themselves to be healthy. The participants in our study recognized themselves to be comparatively healthy, as their perceived health status score was 9.29 out of 15 . These participants not only maintained their good health status to visit the senior welfare centers but were also influenced by their participation in health education, physical activity, and exercise programs operated by the welfare centers. This suggests that when physical activity-related programs are provided in senior welfare centers, differentiated programs need to be offered that consider the type, frequency, and intensity of physical activity and the physical strength of the elderly, with and without diseases. Unfortunately, however, welfare centers are often funded by the city, and funds to operate diverse physical activity programs are limited, which can lead to barriers for the elderly to participate.

The exercise environment did not have a significant effect on physical activity, which differed from the finding of three previous studies (Choe et al., 2008; Dawson et al., 2007; Pan et al., 2009). For the elderly participants of this study, with over $50 \%$ being over age 70 , having easily available exercise environments, such as playgrounds rather than sports centers, or having a home with exercise equipment was a crucial factor in maintaining regular physical activity. Accordingly, suitable policies and institutional support for the elderly to engage in physical activity would encourage creating these environments (e.g., making parks or trails for walking to form a safe environment in local communities) and facilitate physical activity. For example, senior welfare centers offer opportunities because the elderly in the communities spend a lot of their time there, and various programs that promote physical activity can increase the utilization of the facilities.

Although perceived benefits did not affect the physical activity of the elderly significantly, their effect on self-efficacy was significant, which agreed with $\mathrm{Wu}$ and Pender's (2002) study but not with most other studies (Hwang \& Chung, 2008; Ma et al., 2008; Rhodes et al., 1999). We attributed the difference to the fact that over $70 \%$ of the participants performed regular physical activity, and even the other 30\% who did not do regular exercise nevertheless perceived the advantages of physical activity, as shown by their attending health-related lectures and programs of the welfare centers and obtaining information from mass media or other sources.

Perceived barriers showed a significantly negative correlation 
with physical activity but did not significantly influence physical activity directly. In the study of Suh (1999) with arthritis patients and that of Ma et al. (2008) with anxiety patients perceived barriers did not have a significant effect on physical activity. This finding was attributed to the condition that the study participants experienced almost no time, place, or cost barriers preventing them from performing physical activity. In our study, however, participants reported that time, place, cost, and distance were significant barriers to promoting physical activity. The elderly preferred nearby playgrounds to sports centers or health clubs as places to exercise.

Social support did not significantly affect the physical activity of the elderly, but it did directly influence self-efficacy. According to the study of Choi (2005) with middle-aged women, social support was a variable that significantly increased physical activities for leisure. In contrast, the research of Brownson, Baker, Housemann, Brennan, and Bacak (2001) done with female adults, revealed that social support relating to exercise was reduced in middle-aged or older women. Given the almost complete absence of any research on the correlation between social support and physical activity or exercise in the elderly, it is hard to measure the degree of social support perceived by Korean elderly. However, the elderly who received monetary and emotional support from their children or friends had higher self-efficacy than those who do not receive any support. The support elderly receive is a driving force for the maintenance of regular physical activity. Therefore, interventions focusing on social support should be targeted to promote physical activity among elderly who have low self-efficacy.

Pender's HPM has the potential power to expand its use in diverse the age and gives a comprehensive explanation of the psychosocial determinants of physical activity This allows the researcher to develop a unique intervention plan that takes these behaviors into account.

Since this was a study for a group of elderly utilizing senior welfare centers, the findings cannot be generalized to the entire Korean elderly population. Replicated studies with dwelling elders are needed.

\section{Conclusions}

Pender's HPM is very useful in that it takes into account each person's physical activity. In this study, variables significantly and directly influencing the physical activity of the elderly were age, previous exercise behavior, and self-efficacy. The total explanatory power was $37 \%$. Younger age, previous regular exercise, longer period of previous exercise, and higher self-efficacy were associated with more physical activity. The study results support the need to develop programs aimed at enhancing self-efficacy from middle age or, even better, from young adulthood and at facilitating the pleasant and beneficial performance of physical activity by motivating participants to strengthen their activity. In addition, it would be necessary a policy that provide a variety of physical activity promotion program for elderly in public health center.

The following two suggestions are proposed: (1) conduct further research with longer study periods and with more participants who utilize senior citizen centers or who are community-dwelling elderly (2) implement more physical activity promotion programs for the elderly that consider variables such as the intensity, frequency, type of physical activity, and the physical strength of elderly and that incorporate the variables of age, previous exercise behavior, and self-efficacy, which we found in this study to influence the physical activity of the elderly.

\section{References}

Brownson, R. C., Baker, E. A., Housemann, R. A., Brennan, L. K., \& Bacak, S. J. (2001). Environmental and policy determinants of physical activity in the United States. American Journal of Public Health, 91(12), 1995-2003.

Byrne, B. M. (2001). Structural equation modeling with Amos: basic concepts, application, and programming. Mahwah, NJ: Lawrence Erlbaum Associates.

Chang, S. O., Lee, P. S., \& Park, E. Y. (2002). A study on the relationships among the influential variables on stage of change of exercise in the elderly. Journal of Koreas Academy of Nursing, 32(5), 609-623. 
Choe, M. A., Hah, Y. S., Kim, K. S., Yi, M. S., \& Choi, J. A. (2008). A study on exercise behavior, exercise environment and social support of middle-aged women. Journal of Korean Academy of Nursing, 38(1), 101-110.

Choe, M. A., Kim, J. I., Chae, Y. R., Jeon, M. Y., \& You, C. H. (2004). Levels of physical activity and relationship of factors related to physical activity in Korean elderly. Journal of Korean Gerontological Nursing, 6(1), 99-106.

Choi, J. A. (2005). Construction of leisure physical activity model in middle-aged women (Unpublished doctoral dissertation). Seoul National University, Seoul, Korea.

Conn, V. S., Burks, K. J., Pomeroy, S. H., Ulbrich, S. L., \& Cochran, J. E. (2003). Older women and exercise: explanatory concepts. Womens Health Issues, 13(4), 158-166.

Dawson, J., Hillsdon, M., Boller, I., \& Foster, C. (2007). Perceived barriers to walking in the neighborhood environment: A survey of middle-aged and older adults. Journal of Aging and Physical Activity, 15(3), 318-335.

Hotchkiss, L. (1976). A technique for comparing path models between subgroups: Standardized-path regression coefficients. Sociological Methods \& Research, 5(1), 53-76.

Hwang, E. H., \& Chung, Y, S. (2008). Effects of the exercise self-efficacy and exercise benefits/barriers on doing regular exercise of the elderly. Journal of Korean Academy of Nursing, 38(3), 428-436.

Jang, H. J., \& Shin, Y. H. (1999, December). The cultural verification and psychometric evaluation of the exercise benefit/barriers scale for Korean adults with chronic disease. Paper presented at the meeting of the 1st Asian-Pacific Nursing Congress Conference. Seoul, Korea.

Kim, K. J. (2000). Prediction model for health promotion behaviors in middle-aged men (Unpublished doctoral dissertation). Hanyang University, Seoul, Korea.

Korea National Statistical Office. (2010). Elderly statistic in Korean 2007 year. Seoul Korea: Author.

Korean Ministry of Health and Welfare. (2010). Report on National Health and Nutrition Survey 2008. Seoul, Korea: Author.

Lawstone, M. P., Moss, M., Fulcomer, M., \& Kleban, M. H. (1982). $\mathrm{A}$ research and service oriented multi-level assessment instrument. Journal of Gerontology, 37(1), 91-99.

Lee, M. R. (1999). A model for exercise behavior in early-middle aged women (Unpublished doctoral dissertation). Chungnam National University, Taejon, Korea.

Lee, P. S., \& Chang, S. O. (2001). The study on the effect of stage based exercise motivational intervention program for the elderly. Journal of Korean Academy of Nursing, 31(5), 818-834.

Lee, S. M. (1990). Covariance structure analysis. Seoul, Korea: Seongwonsa.

Lee, Y. S., \& Laffrey, S. C. (2006). Predictors of physical activity in older adults with borderline hypertension. Nursing Research, 55(2), 110-120.

Ma, W. F., Lane, H. Y., \& Laffrey, S. C. (2008). A model testing factors that influence physical activity for Taiwanese adults with anxiety. Research in Nursing \& Health, 31(5), 476-489.

Marcus, B. H., Selby, V. C., Niaura, R. S., \& Rossi, J. S. (1992). Self-efficacy and the stage of exercise behavior change. Research Quarterly for Exercise \& Sport, 63(1), 60-66.

Pan, S. Y., Cameron, C., Desmeules, M., Morrison, H., Craig, C. L., \& Jiang, X. (2009). Individual, social, environmental, and physical environmental correlates with physical activity among Canadians: a cross-sectional study. BMC Public Health, 9, 1-12.

Park, H. S., Kim, Y. J., Kang, I. S., \& Park, K. Y. (2007). Management in chronic disease. Seoul, Korea: Jungdam.

Pender, N. J. (1996). Health promotion in nursing practice (3rd ed.). Stamford, CT: Appleton \& Lange.

Preacher, K. J., Cai, L., \& MacCallum, R. C. (2007). Alternatives to traditional model comparison strategies for covariance structure models. In T. D. Little, J. A. Bovaird, \& N. A. Card, (Eds.), Modeling contextual effects in longitudinal studies(pp.33-62). Mahwah, NJ: Lawrence Erlbaum Associates Publishers.

Rhodes, R. E., Martin, A. D., Taunton, J. E., Rhodes, E. C., Donnelly, M., \& Elliot, J. (1999). Factors associated with exercise adherence among older adults: An individual perspective. Sports Medicine, 28(6), 397-411.

Sallis, J. F., Grossman, R. M., Pinski, R. B., Patterson, T. L., \& Nader, P. R. (1987). The development of scales to measure social support for diet and exercise behaviors. Preventive Medicine, 16(6), 825-836.

Sallis, J. F., \& Hovell, M. F. (1990). Determinants of exercise behavior. Exercise and Sports Science Reviews, 18, 307-330.

Sechrist, K. R., Walker, S. N., \& Pender, N. J. (1987). Development and psychometric evaluation of the exercise benefits/barriers scale. Research in Nursing \& Health, 10(6), 357-365.

Shin, K. R., Kang, Y. H., Park, H. J., Cho, M. O., \& Heitkemper, M. (2008). Testing and Developing the Health Promotion Model in Low-Income, Korean Elderly Women. College of Nursing Science. Q, 21, 173-178.

Speake, D. L., Cowart, M. E., \& Pellet, K. (1989). Health perceptions and lifestyles of the elderly. Research in Nursing \& Health, 12(2), 93-100.

Suh, G. H. (1999). Prediction model of exercise behaviors in patients with arthritis (Unpublished doctoral dissertation). Hanyang University, Seoul, Korea.

Warburton, D. E., Nicol, C. W., \& Bredin S. S. (2006). Health benefits of physical activity: The evidence. Canadian Medical Association Journal, 174(6), 801-809.

Washburn, R. A., Smith, K. W., Jette, A. M., \& Janney, C. A. (1993). 
The physical activity scale for the elderly (PASE):Development and evaluation. Journal of Clinical Epidemiology, 46(2), 153-162.

Wu, B., \& Porell, F. (2000). Job characteristics and leisure physical activity. Journal of Aging and Health, 12(4), 538-559.
Wu, T. Y., \& Pender, N. (2002). Determinants of physical activity among Taiwanese adolescents: an application of the health promotion model. Research in Nursing \& Health, 25(1), 25-36. 